\title{
ENVIRONMENTAL RECOVERY AND SOCIAL AND URBAN REHABILITATION. CHARACTERIZATION AND DECISION FACTORS FOR REVITALIZATION WORKS OF THE MINDU STREAM
}

\author{
Welyton Monteiro da Silva ${ }^{1}$, Italo Jorge Tavares Jimenez ${ }^{2}$, Priscila Bentes Damasceno ${ }^{3}$, Charles \\ Ribeiro de Brito ${ }^{4}$
}

\author{
${ }^{1,4}$ Centro Universitário do Norte - UNINORTE - Laureate Universites, Brasil, Rua Igarapé de Manaus, 211 - Centro, \\ Manaus/AM. \\ 2,3 Instituto de Tecnologia e Educação Galileo da Amazônia (ITEGAM), Av Joaquim Nabuco, 1950 - Centro, \\ Manaus/AM.
}

Email: welytonmonteirosilva@gmail.com, italo.jimenez@itegam.org.br, priscilabentes.d@hotmail.com, charles.brito@uninorte.com.br.

Received: March 04th 2019

Accepted: April $25^{\text {th }}, 2019$

Published: June $30^{\text {th }}, 2019$

Copyright (02016 by authors and Institute of Technology Galileo of Amazon (ITEGAM).

This work is licensed under the Creative Commons Attribution International License (CC BY 4.0). https://creativecommons.org/lice nses/by/4.0/

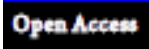

\section{ABSTRACT}

With global pressure caused by man-made abuses often fraught with environmental impacts, world leaders have been strongly influenced to harmonize the way humans occupy the space they inhabit. This scenario results that the Public Administration reaches the most diverse locations with a view to promoting a better integration of man into the environment. In this sense, Brazil has developed, in recent years, improved legislation that affects local policies. In the municipality of Manaus, efforts have been made in this way to sustain through legislation guidelines the scope of this improvement. As an example of a search for adequacy with the laws and regiments, the Municipality of Manaus has begun the revitalization of the banks of the Mindu stream. This study sought to understand the reasons that encouraged the emergence of this municipal project. Initially a section was chosen for a more detailed analysis. Problems of socio environmental interaction were identified that caused stimulation in Public Management. To do so, we used the technical surveys made for the area in question, in order to provide a critical opinion on the data used as a starting point in planning the changes in the implementation process. The results contribute to the understanding of how civil works are important intervention tools of the Public Power, given their potential of multidisciplinary aspect in a single administrative act.

Keywords: environmental impact, public intervention, urban engineering.

\section{RECUPERAÇÃO AMBIENTAL E REQUALIFICAÇÃO SOCIAL E URBANÍSTICA. CARACTERIZAÇÃO E FATORES DECISÓRIOS PARA OBRAS DE REVITALIZAÇÃO DO IGARAPÉ DO MINDU}

\section{RESUMO}

Com a pressão em nível global causada pelos abusos cometidos pelo homem desdobrados por muitas vezes em impactos ambientais, os líderes mundiais têm sofrido forte influência para harmonizar o modo como o ser humano ocupa o espaço em que habita. Esse cenário resulta que a Administração Pública chega às mais diversas localidades com vistas a promover uma melhor integração do homem ao meio ambiente. Nesse sentido o Brasil desenvolveu, em anos recentes, uma legislação aprimorada que atinge as políticas locais. No município de Manaus, têm sido dessa maneira, empreendidos esforços de sustentar por meio de legislação orientações o alcance desta melhoria. Como exemplo de busca por adequação com as leis e regimentos a Prefeitura Municipal de Manaus deu início ao trabalho de revitalização das margens do Igarapé do Mindu. Buscou-se neste estudo compreender os motivos que incentivaram o surgimento desse projeto municipal. Inicialmente escolheu-se um trecho para uma análise mais detalhada. Foram identificados problemas de interação socioambiental que causaram estímulo na Gestão Pública. Para tanto se recorreu aos levantamentos técnicos feitos para área em questão, de modo a tecer um parecer crítico sobre os dados usados como ponto de partida no planejamento das mudanças em processo de implantação. Os resultados contribuem para o entendimento de como obras civis são importantes ferramentas de intervenção do Poder Público, dado seu potencial de aspecto multidisciplinar em um único ato administrativo.

Palavras-Chaves: impacto ambiental, intervenção pública, engenharia urbana. 


\section{INTRODUÇÃO}

São temas recorrentes, tanto nos meios científicos, quanto nos midiáticos, os fatos ligados ao uso exploratório do planeta praticado pelo homem e os impactos decorrentes dessa interação.

Em virtude dos limites que o homem desrespeita na relação entre o meio ambiente e os valores econômicos com ênfase na obtenção de lucros, pode-se chegar a um colapso em que o meio não seja mais capaz de suprir às necessidades da cadeia produtiva [1]. Uma base dessa argumentação indica o uso dos recursos naturais sem que estes recursos tenham condições ou tempo hábil o suficiente para seu restabelecimento.

Apesar de [2] não compartilhar exatamente da opinião dos ecólogos no que tange às consequências do desrespeito desses limites da interação economia $\mathrm{x}$ recursos naturais, por meio do autor é plausível sugerir que um dos fatores de favorecimento da dinâmica econômica é o deslocamento da mão de obra produtora de bens de consumo. $\mathrm{O}$ autor reconhece os elementos que subsidiam os modelos de economia desenvolvidos em cada contexto, e aponta como integrante dessa dinâmica a atuação do homem por sua capacidade. Mesmo que neste ponto faça referência à cognição, não se pode isolar a capacidade cognitiva das variáveis que nela influenciam.

Os autores [3] informam que dentre estas variáveis encontram-se aquelas associadas à busca de qualidade de moradia que tem por objetivo minorar a exclusão social no sentido que a sociologia conceitua atualmente. A ideia transmitida por este conceito abrange dentre outros aspectos a falta de acesso a bens, serviços e valores e direitos sociais, e tem em seu âmago a precariedade da cidadania.

Desse modo, os centros urbanos tornaram-se focos de sistemas produtivos, assim é compreensível vivenciarmos os deslocamentos demográficos em função da demanda produtiva, [4] apontam que em 2000 a população urbana brasileira já era de $81,2 \%$, e passou para $83,8 \%$ em 2008 . Em outras palavras, passou a um valor ínfimo de praticamente $10 \%$ da população de nosso país o que reside atualmente em zonas rurais.

$\mathrm{Na}$ observação de [5] as cidades desenvolvem-se como epicentros de valores sociais, técnicos e capitalistas, e ao mesmo tempo em que concede benefícios, explora potencial produtivo em troca.

O que se observa é um ciclo da cadeia produtiva em que o surgimento dos bens de consumo precisa de toda uma estrutura que o mantenha em funcionamento, daí são geradas oportunidades para as pessoas atuarem de modo direto ou indireto. Como essas situações se ajustam em polos, em termos geográficos, as pessoas são atraídas pela expectativa de reduzir a exclusão social. Assim, surge uma causa bastante relevante para o deslocamento populacional mencionado.

Uma marca da expansão das grandes cidades que se tornam metrópoles devido ao exponencial adensamento populacional oriundo do êxodo rural é uma dificuldade de compatibilização entre o contingente, continuamente crescente, e a manutenção do papel do Estado e das condições que por esse devem ser providas para cumprimento daquilo que se espera em uma sociedade de valores democráticos e desenvolvimentista.

Em relação a Manaus, essa realidade é experimentada no período áureo da borracha e com a implantação e posterior consolidação da Zona Franca [6].

Ao citar os autores [7] sugerem que o porquê de haver uma ocupação de áreas, que em períodos de intempéries, oferecem risco à integridade física ou mesmo à vida dos moradores, está no fato de que nem todos estão em condições financeiras de morar nas zonas da cidade em que os serviços de prestação coletiva e o conforto sejam mais efetivos.

O povoamento das margens dos igarapés de Manaus passou por essas ocupações, de forma que estas áreas sofreram uma ação antrópica desordenada, à semelhança do que se deu em outras cidades de caráter metropolitano [8].

Nesse contexto, o presente trabalho procurou identificar a relevância com que a Engenharia Civil, contribui para que a busca dos anseios da sociedade possa ser alcançada ou atenuada por caminhos que apresentem maior eficiência, de modo a obter-se com isso a melhor relação custo $\mathrm{x}$ benefício possível.

Num caso mais particular, dentre ações tomadas pela gestão do Município de Manaus, está o plano de revitalização das margens do Igarapé do Mindu, ao qual, procurou-se nesse documento, analisar os motivos que o ensejaram em âmbito externo (legislação e pressão social) e interno (índices e estatísticas), para daí então evidenciar a participação que a Engenharia Civil tem proporcionado, pois transcende das realizações materiais para um meio pelo qual o Poder público não realiza construções meramente, e sim alcança metas e objetivos com amplitude multifuncional, e atinge dessa maneira diversas vertentes de necessidade.

\section{MATERIAL E MÉTODOS}

A análise feita nesse trabalho observa dois panoramas para uma melhor construção da ideia a que se propõe. Em outras palavras, o que se pratica aqui são observações pontuais do Igarapé do Mindu, um importante corpo hídrico que compõe a geografia do município de Manaus, localizado na bacia do São Raimundo, que na Figura 01 aparece em coloração marrom.

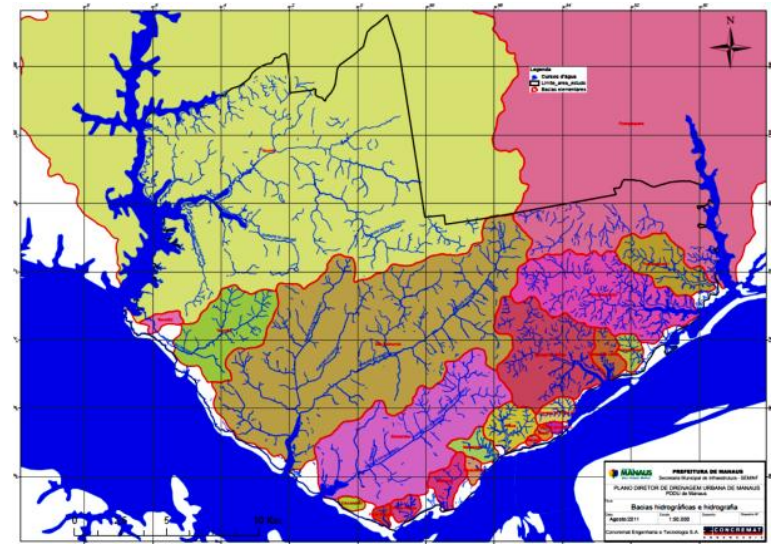

Figura 1: Principais Bacias hidrográficas de Manaus. Fonte: Adaptado de [9].

No decorrer de seu percurso o referido igarapé faz conexão entre duas reservas ambientais, são elas o Parque Municipal do Mindu e a Reserva Particular do Parque Natural Honda. Há entre as duas reservas um Corredor Ecológico criado pelo Decreto $\mathrm{N}^{\circ}$ 9.329 de 26 de outubro de 2007, que além de descrever o perímetro compreendido pelo referido corredor, visa a prática de ações de cunho ambiental e a previsão de intervenção por parte do poder público na recuperação das áreas sujeitas à degradação por ação do homem, e determina como uso possível do solo compreendido por essa área, somente àquele para estruturas voltadas para a prática de lazer que permitam uma integração homem/meio ambiente positiva. Dessa forma também se escolheu a Avenida Nathan Xavier de Albuquerque, pelo fato de atravessar o Corredor Ecológico na intenção de manter a responsabilidade política assumida.

A figura 2 mostra a Avenida Nathan Xavier de Albuquerque (realce vermelho), que faz atualmente ligação entre a Avenida 
Governador José Lindoso (lado direito da popular Avenida das Torres, no sentido Centro-Bairro) e a Rua João Câmara na Colina do Aleixo.

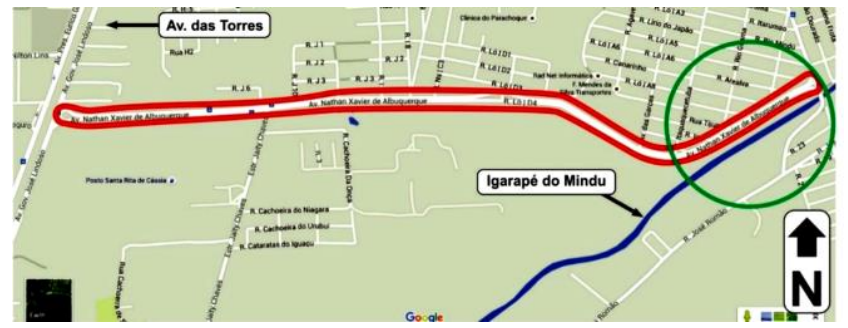

Figura 2: Localização da Avenida Nathan Xavier de Albuquerque Fonte: (2015), [10].

O trecho em estudo está contido no círculo verde e as coordenadas são: $3^{\circ} 03^{\prime} 42,7^{\prime \prime} \mathrm{S}$ e $59^{\circ} 57^{\prime} 43,7^{\prime \prime} \mathrm{W}$ (encontro com a Rua João Câmara) $3^{\circ} 03^{\prime} 59,33^{\prime}$ S e 59 57'58,8” W (encontro com a Rua Itaquaquecetuba).

$\mathrm{O}$ método de pesquisa aqui utilizado foi fundamentalmente bibliográfico, pesquisa em meio eletrônico, leitura e uso de artigos científicos, legislação concernente no cenário brasileiro e local e consulta à literatura especializada na temática voltada para o planejamento hidrológico, para uma melhor compreensão dos conceitos e métodos hidráulicos e hidrológicos.

Também houve a cessão de documentos técnicos por parte da Secretaria de Infraestrutura da Prefeitura Municipal de Manaus SEMINF, de maneira direta, neste caso a principal fonte foi o Projeto de Recuperação Ambiental e Requalificação Social e Urbanística do Igarapé do Mindu, ou de maneira indireta, por meio do Plano Diretor de Drenagem Urbana de Manaus (PDDU de Manaus) disponível ao público geral no site da secretaria mencionada.

Com o intuito de coletar material documental fotográfico da Av. Nathan Xavier de Albuquerque, foi efetuada uma visita a campo no período do dia 14 a 30/11/2017, sem acompanhamento e com permanência no local entre os horários de 08:00h às 10:00h. $\mathrm{O}$ trecho de interesse foi percorrido para verificação de projeto de drenagem, conforme projeto preliminar, também houve verificação da funcionalidade da restrição da APP e condições de pavimentação do trecho.

O uso de softwares também se necessário para a verificação do contexto da localidade escolhida. Para as análises referentes às chuvas que influem sobre o igarapé do Mindu. Foi utilizado o software HidroWeb 1.2, desenvolvido pela Agência Nacional de Águas - ANA para acompanhamento de fenômenos hidrometeorológicos. Para elaboração de um gráfico comparativo entre dois postos pluviométricos da região se fez uso do Microsoft Excel. Na análise da avenida Nathan Xavier de Albuquerque, utilizou-se software AutoCAD na versão 2D e visualizações via satélite pelo suporte do servidor Google, o Google Maps. Para a adaptação de alguns elementos gráficos utilizou-se o Corel Draw $X 7$ e para a edição de fotografias o Snagit Editor.

\section{RESULTADOS}

Uma realidade bem evidente é o de contaminação do igarapé por resíduos sólidos nele despejados. Em sua maioria resíduos de sacolas, sacos e garrafas plásticas. Também se verificam esporadicamente móveis e eletrodomésticos.

Pelo volume de lixo observado é possível inferir que resíduos químicos também agravam as condições do leito e em conjunto, podendo esses facilitar a propagação de agentes patogênicos de veiculação hídrica.
A figura 3 caracteriza a interação homem/meio ambiente ao expor uma cena veiculada em mídia local em que uma moradora despeja lixo doméstico diretamente na correnteza do igarapé.

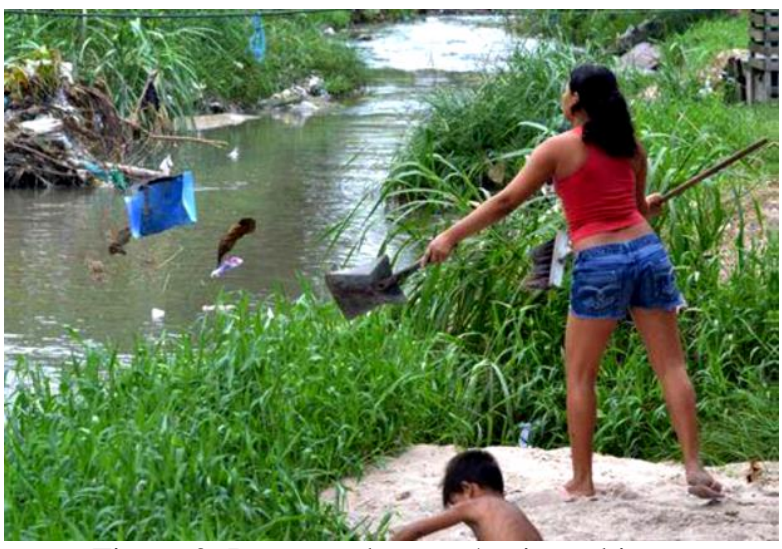

Figura 3: Interação homem/meio ambiente.

Fonte: Autores, (2017).

Como pode se observar na figura 3 , uma moradora despeja diretamente na correnteza do igarapé do Mindu, lixo doméstico. Toda residência regularmente habitada é fonte de contaminação química (óleo de cozinha, pilhas, cosméticos, etc.), além de resíduos sólidos. É possível apontar ocupação inadequada, uso indiscriminado e deterioração das margens como efeitos intermediários que dão causa aos finais.

Infere-se, que é a ação antrópica a principal fonte dos efeitos intermediários e finais de degradação ambiental. Mesmo ao se observar a realidade manauara atual, na qual os gestores têm procurado agir de modo a mitigar essas mazelas, ainda é notória a exploração inconsciente do meio ambiente por parte do homem.

A figura 4 exemplifica o resultado cumulativo de ações como a mencionada e informa que em uma ação de limpeza, em um trecho de aproximadamente $150,00 \mathrm{~m}$ houve a retirada cerca de 25 toneladas de lixo. $\mathrm{Na}$ imagem é possível distinguir pedaços de madeira e predominantemente materiais plásticos.

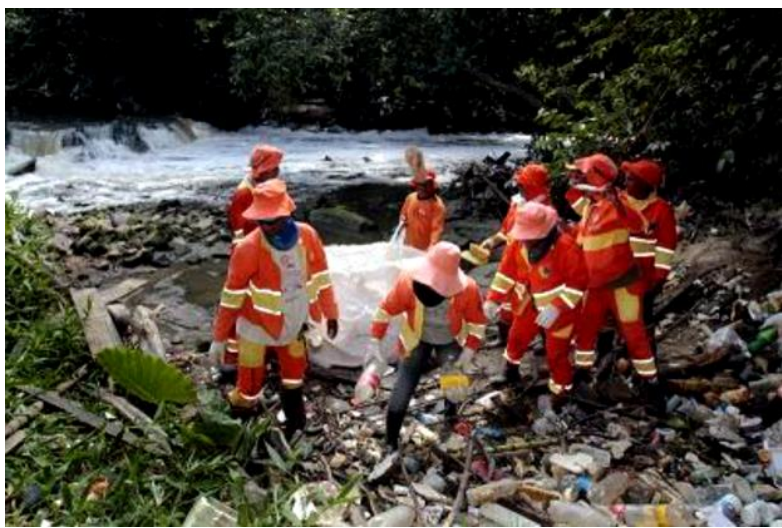

Figura 4: Operação de limpeza no igarapé do Mindu. Fonte: Autores, (2017).

Além disso, há ainda uma proporção de impactos ambientais que pode ser encarada como alarmante, um bom exemplo, é o resultado acumulado não só de ação dos moradores das margens do Mindu, mas de qualquer um que tenha a chance de interagir com o igarapé, visto por meio da figura 4.

Na figura 5, vê-se um percurso em estágio de implementação do projeto de revitalização, no qual ainda é possível constatar a presença de muitos resíduos plásticos, dentre outros. 


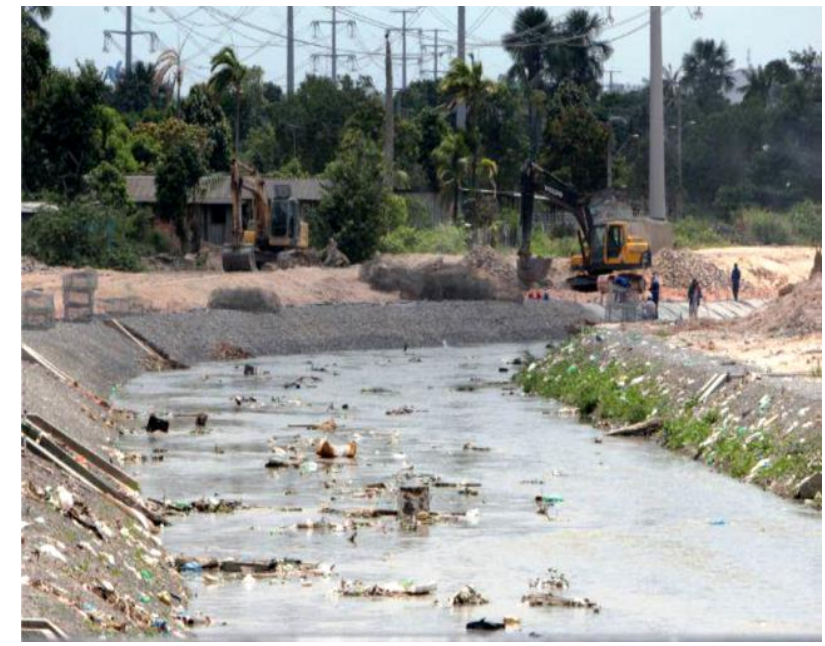

Figura 5: Obras de Engenharia do processo de revitalização do Mindu.

Fonte: [11].

A figura 5 exibe um trecho onde o processo de revitalização do Mindu encontra-se em bom andamento, com a seção do canal uniformizada e a implantação dos gabiões nas margens. Ainda assim, há presença de resíduos sólidos, o que é um precedente para a dedução de resíduos orgânicos excessivos, até mesmo denotado pela turbidez que a água costuma apresentar, e de resíduos químicos.

Na figura 6 é possível ver o lixo arrastado e posteriormente depositado próximo a base da Ponte da Feira do Mutirão. Esta ponte permite a transposição do igarapé do Mindu, também se observa a quantidade acentuada de sedimentos e o leito do igarapé em processo de assoreamento.

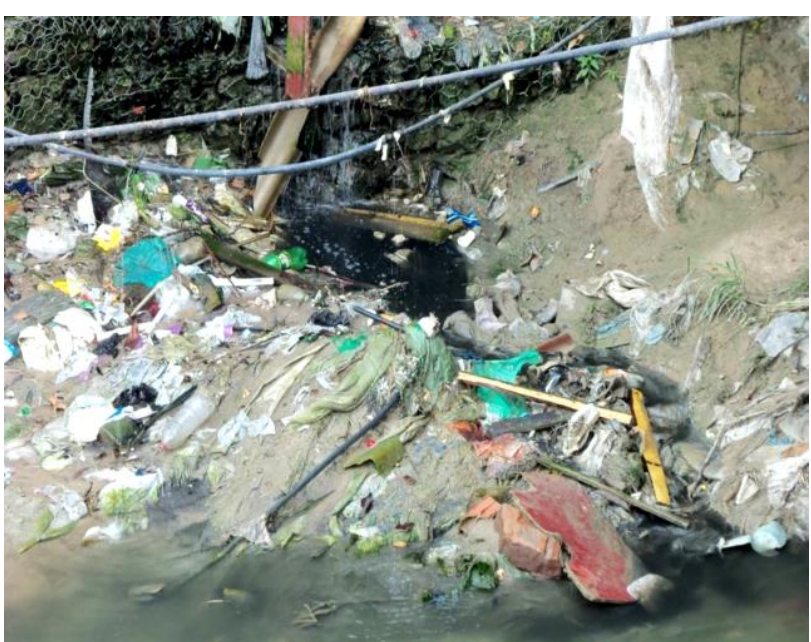

Figura 6: Lixo e sedimentos acumulados a baixo da ponte na rua da Feira do Mutirão (rua Itaeté).

Fonte: Autores, (2017).

Ainda em decorrência da deterioração das margens com efeitos de erosão, outro impacto negativo é verificação do fenômeno de assoreamento acentuado, sempre presente nos igarapés que têm suas margens exploradas de modo exacerbado. Por meio da figura 6 é possível ver esse processo que é recorrente em diversos trechos do igarapé, o exemplo em questão está em um bairro vizinho ao bairro onde fica a Av. Nathan Xavier de Albuquerque. A extensão do igarapé do Mindu entre o ponto em que fica esta ponte e o cruzamento com a referida avenida é de aproximadamente $2,63 \mathrm{~km}$ como se vê na figura 7 .

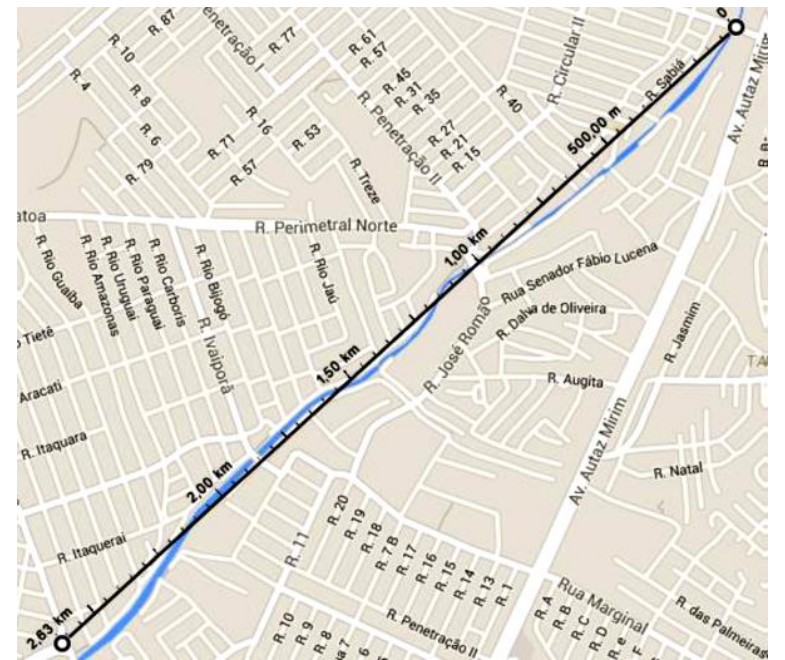

Figura 7: Distância entre a Feira do Mutirão e início da Av. Nathan Xavier de Albuquerque.

Fonte: [10].

A figura 8, consta na Ação Civil Pública de $\mathrm{n}^{\circ}$ 2009.32.00.002520-6, movida em 2009 pelo Ministério Público Federal no Amazonas. No episódio, a Prefeitura de Manaus executava procedimento de dragagem do leito do igarapé do Mindu e depositava o material retirado sobre suas margens.

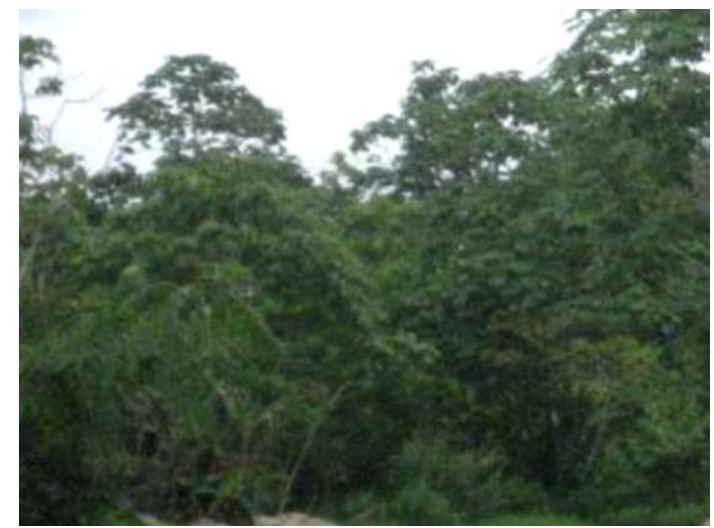

Figura 8: Sedimentos dragados e depositados sobre as margens do igarapé do Mindu.

Fonte: Fonte: Autores, (2017).

Mesmo o Poder Público, frente aos desafios do desordenado crescimento urbano acaba por ser agente no processo de degradação, ainda que esporadicamente, é o que se evidencia pela figura 8, no episódio, a ação da Prefeitura de Manaus é incompatível com o esperado, pois no procedimento de dragagem do igarapé do Mindu, os sedimentos foram depositados sobre a margem, de modo a destruir a mata ciliar, também protegida pelo Código Florestal. Esse é o caso de um dano derivado, pois em decorrência da intensificação da erosão ocorrida a montante do igarapé, houve a demanda de uma atuação com vistas a redução de risco de inundação, esta, por sua vez, praticou-se de modo inadequado, como mencionado.

É esse desenvolvimento desequilibrado com ênfase em certos valores em detrimento de outros que gera situações como as que podem ser vistas em muitas cidades desenvolvidas economicamente, porém com estrutura de suporte social deficitário ante às demandas de dignidade da pessoa humana. Um caso bem antagônico, pois se a busca era por dignidade, o que passa a ser presenciado é uma evidenciação de desagregação social.

À medida que os recursos ficaram mais escassos, ou alterados em suas características, começou um despertamento para essas 
questões, pois a indústria rudimentar e a expansão naval do início de processo de colonização por parte da Europa, fez surgir a preocupação de como seria administrada a questão da escassez [12].

Numa tentativa de combater os males até agora elencados, e também em parte pela evolução da sensibilidade ambiental em nível global, o Brasil tem empreendido iniciativas de cunho protetivo, por meio de legislação e programas sociais.

No que tange a recursos hídricos, é possível separar fragmentos da Constituição Federal de 1988 [13] e de outras leis, sem a intenção de uma explanação taxativa, porém elucidativa somente, com propósito de um entendimento contextual. Compete à União a defesa dos corpos hídricos e a todos os entes da Federação a defesa do meio ambiente. A CF/88 [13] é o ponto de partida para diversos dispositivos legais, e dela derivam desdobramentos de atuação nas esferas federal, estadual e municipal. Em âmbito federal é interessante mencionar a lei $\mathrm{n}^{\mathrm{o}}$ 9433/97 que define a Política Nacional de Recursos hídricos. Desta, destaca-se neste trabalho o artigo $3^{\circ}$ inciso II que prevê ações que coadunem múltiplos tipos de diversidades de foco de interesse, inclusive as de: características físicas, econômicas, culturais dentre outras [14].

Aqui surge a previsão de busca pelo equilíbrio entre os diversos elementos que ocupam o espaço geográfico. E no artigo $7^{\circ}$ inciso $\mathrm{X}$, aparece o dispositivo que prevê a criação das reservas que compõe a orla dos cursos d'água.

Com a previsão das áreas destinadas à reserva, abre-se oportunidade para o amparo legal de proteção das margens dos corpos hídricos, o que acontece atualmente por meio da lei que define o Código Florestal, Lei $\mathrm{n}^{\circ} 12.651 / 12$. Aqui está orientada a atual concepção de Área de Preservação Permanente - APP [15].

Mais um exemplo de interação homem/meio ambiente, a figura 9 mostra a ação das águas do igarapé do Mindu em processo de erosão na base de uma residência. Note-se mais uma vez a presença de resíduos sólidos de natureza diversa.

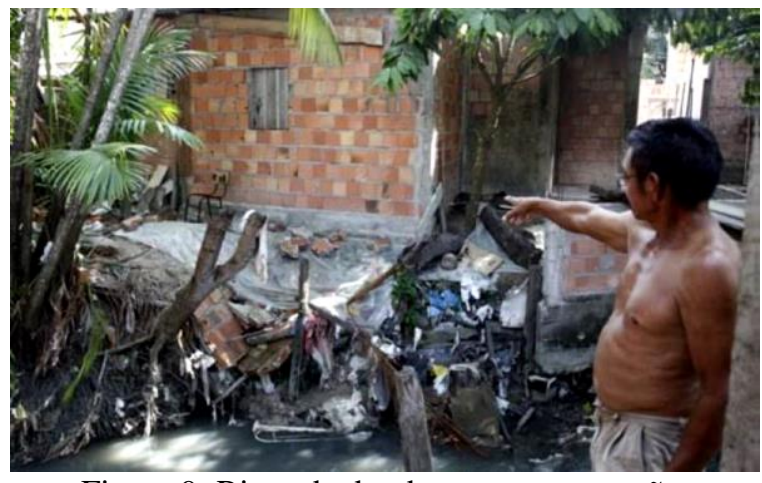

Figura 9: Risco de desabamento por erosão. Fonte: Autores, (2017).

Neste contexto, pode-se entender que esse (figura 9) seja mais um caso de impacto ambiental dos elementos naturais em efeito de reação sobre o homem.

De acordo com o decreto que cria o projeto de revitalização do igarapé, as famílias residentes das margens receberiam indenização para deixar o local. Por meio da figura 10, é possível visualizar que a margem situada na comunidade Mutirão possui uma extensa área já desocupada e com imóveis já demolidos para posterior intervenção (contorno em evidência). Também é possível notar na margem onde fica o bairro Tancredo Neves, o ainda presente adensamento populacional que caracteriza boa parte do trajeto deste curso d'água.

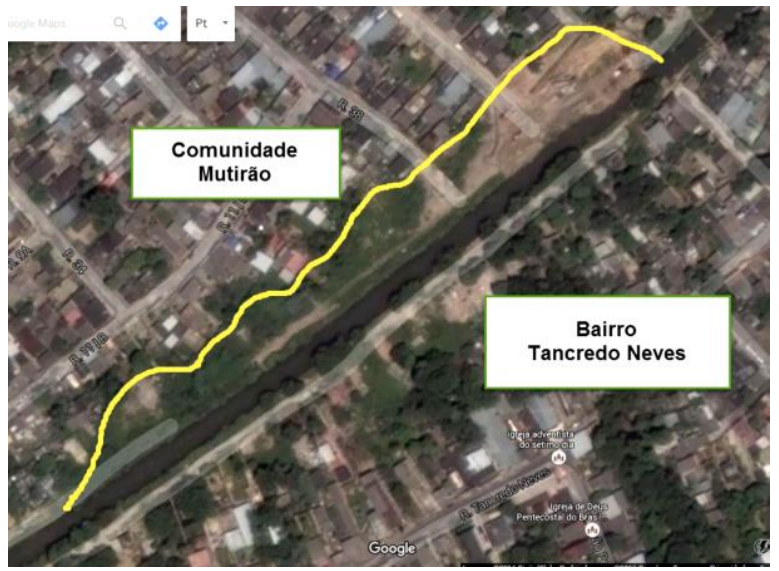

Figura 10: Etapa de desapropriação.

Fonte: (2017), [10].

A figura 10 exemplifica uma realidade que se estende por muitos trechos do igarapé do Mindu, em que as margens dos dois lados são ocupadas por denso povoamento, na imagem em questão percebe-se uma clareira e também uma área com cobertura vegetal sobre o solo, indicativo da ação de intervenção do Poder Público em cumprimento à etapa de desapropriação das famílias prevista no Decreto ${ }^{\circ} 1.532 / 12$ [16].

$\mathrm{Na}$ Figura 11 tem-se um infográfico que explana os critérios que definem os limites das áreas de preservação permanente, ou APP's, que margeiam corpos hídricos. Este indica, que a partir das nascentes, deve haver uma distância radial de 50,00m. Em sequência, para seções de cursos d'água de até $10,00 \mathrm{~m}$ deve ser oferecida à APP uma margem de $30,00 \mathrm{~m}$ e à medida que o curso fica mais largo, a ponto de ultrapassar 600,00m, reservar-se-á o espaço de 500,00m.

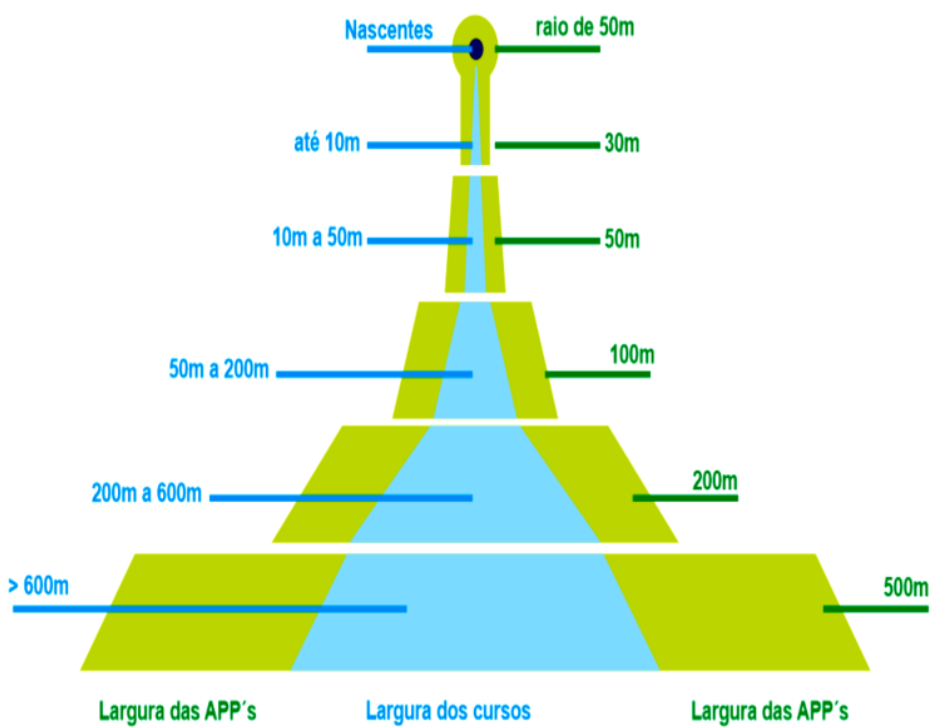

Figura 11: Limites em distância radial para as APP's.

Fonte: Adaptado de [17].

A figura 11 é um modo bem didático de compreender como se delimita a APP, à medida que o curso de água se expande.

Porém o que se observa na figura 12 é um caso de aplicação da orientação transmitida pelo infográfico. 


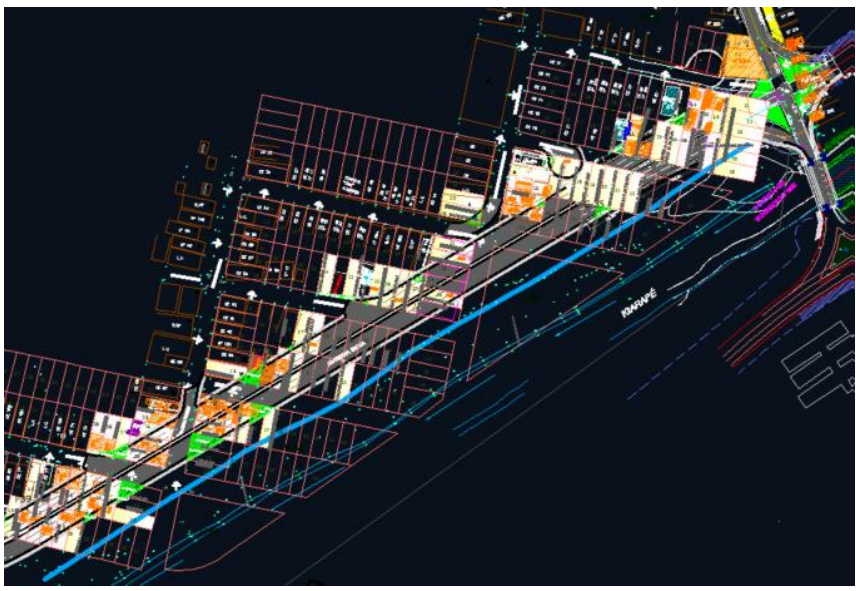

Figura 12: Av. Nathan Xavier com sobreposição dos lotes ocupados na área em 2007.

Fonte: [18].

A partir da margem do Igarapé do Mindu desloca-se uma linha azul, mais espessa que as demais, a uma distância de 30,00, conforme indicado para seções de até $10,00 \mathrm{~m}$ de largura.

Ao analisar a imagem é ser notório que ocorria uma proliferação de ocupação irregular de área reservada. Referente à avenida implantada, o que é visto deve ser contrastado com a legislação municipal, pois, a seção do igarapé no trecho em questão ultrapassa $10,00 \mathrm{~m}$, e torna a distância de $30,00 \mathrm{~m}$ incompatível com o estabelecido pelo Código Florestal, que determina para o caso o comprimento de 50,00m. Em Manaus, o artifício legal que regula a revitalização do Mindu é o Decreto $n^{\circ} 9.332 / 07$, posteriormente atualizado pelo Decreto $\mathrm{n}^{\mathrm{o}} 1.532 / 12$. Em seu texto, o decreto delimita a APP para o valor de $30,00 \mathrm{~m}$ e destina os $20,00 \mathrm{~m}$ restantes para a criação de espaços para benefício social e interação saudável entre o homem e a biota [19].

Conforme exposto pelo Decreto $n^{\circ}$ 9.332/07, destina-se estritamente à APP o comprimento de $30,00 \mathrm{~m}$ e torna-se passível a intervenção nos 20,00m restantes, isso mantém a legalidade do referido decreto, por haver no Código Florestal essa flexibilização quanto ao uso mesmo das APP's desde que mantenha um objetivo ecológico e/ou social como orientado pelo artigo $1^{\mathrm{o}}$-A.

Por meio da figura 12, a partir da rua João Câmara, pode-se contar aproximadamente 60 imóveis que ultrapassam o limite da APP, identificado no desenho pela linha azul de espessura mais densa. Por sua vez indica que no local onde a referida avenida foi implantada, ocorria a proliferação de moradias em condições de irregularidade em relação ao Código Florestal e ao Decreto que orienta a revitalização do mencionado igarapé.

Compreendidas as circunstâncias que ensejavam atuação do Poder Público, é apropriado reiterar que uma definição corriqueira entre os doutrinadores e juristas é a de que para o Estado, suas ações são impostas e pautadas pela lei, de maneira que haja assim, todo um pano de fundo que contextualiza os seus atos e os liga a valores de responsabilidade com os serviços prestados e a eficiência dos mesmos conforme esclarece o artigo 37 da Constituição Federal de 1988 [20].

A figura 13 é resultado de um estudo hidrológico que usa a absorção da bacia de contribuição do Mindu para indicar como o igarapé reagiria em 2007, a uma chuva com TR de 25 anos com duração de 6 horas [18]. Há também uma localidade indicada na qual ocorreu, no mesmo ano, uma inundação. É interessante observar que a imagem não apresenta todo o igarapé, porém somente o bairro de São Jorge e a avenida Jornalista Umberto Calderaro (antiga Av. Paraíba). Há na imagem um círculo vermelho que assinala uma localidade da comunidade Vila Amazonas, que sofreu uma inundação em abril daquele ano.

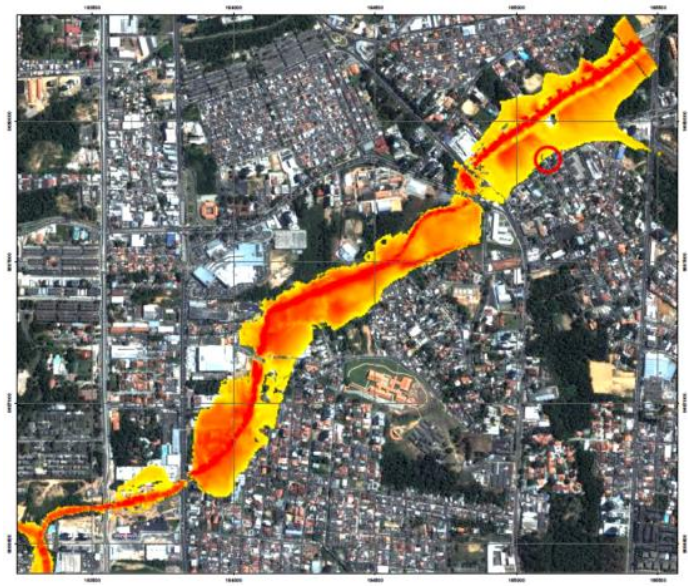

Figura 13: Trecho do igarapé com maior risco de alagamentos em 2007.

Fonte: [18].

$\mathrm{Na}$ figura 14 é retratada a inundação indicada na imagem anterior. Abril é um dos meses com índices pluviométricos mais elevados para a região, e foi justamente neste mês em que ocorreu o transbordo do igarapé ao nível que pode ser observado.

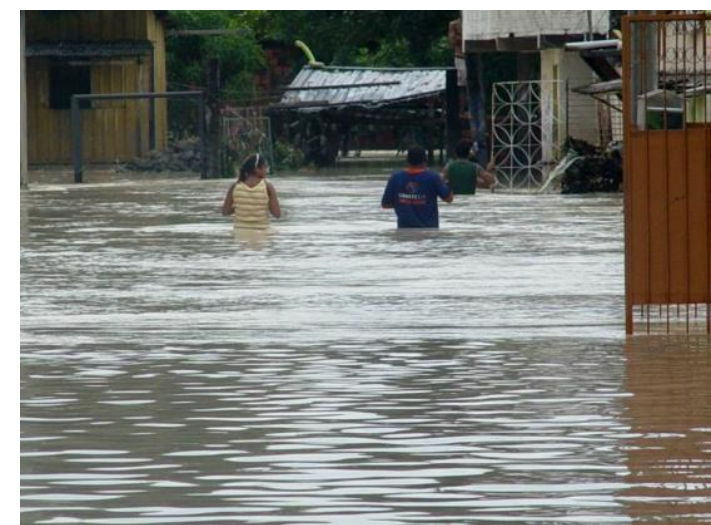

Figura 14: Inundação na Comunidade Vila Amazonas em abril de 2007.

Fonte: [21].

Para uma compreensão mais pragmática da leitura de um hidrograma, a figura 14 pode ser apontada como um caso em que o hidrograma do local seria um do tipo pontiagudo que indica um rápido tempo de concentração com acúmulo acelerado de precipitação.

Como alternativa para uma harmonização entre o homem e o meio ambiente, faz-se necessário o desenvolvimento de um sistema de condução, tanto para o esgotamento, como de um para as águas pluviais de maneira que contorne deficiências da topografia natural e corrija o modo como o homem pratica a ocupação do solo [22].

Com fatores que envolvem elementos naturais e físicos e ao mesmo tempo necessidades sociais, ambientais e econômicas. $\mathrm{O}$ Administrador tem diante de si, uma tarefa hercúlea que carece de competências multidisciplinares [23].

A análise de uma obra de engenharia possibilita um vislumbre dos benefícios possíveis e dos realmente alcançados com a aplicação de competências necessárias. A obra de execução da Av. Nathan Xavier de Albuquerque tipifica a convergência de uma gama de interesses e concilia ânsias sociais e ambientais.

Para um entendimento da importância desta obra neste aspecto, é interessante conhecer sua localização. Em sequência há a figura 15 em que as águas turvas do Mindu fazem ruir uma casa. 
Há várias outras palafitas sob o mesmo risco, pois estão na mesma condição de invasão do leito elevado por ocasião de uma chuva intensa.

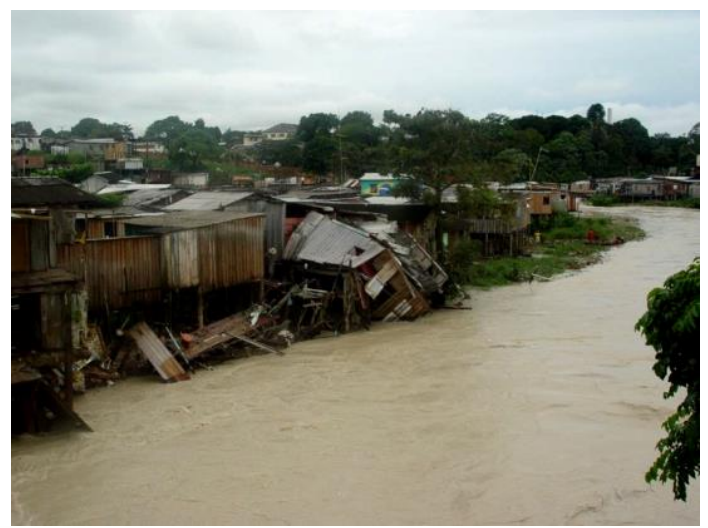

Figura 15: Desabamento após chuva intensa. Fonte: Autores, (2017).

As figuras 14 e 15 são reflexos desse tipo de ocupação. Áreas antes naturalmente sujeitas a alagamento de modo sazonal sofreram um processo de supressão e impermeabilização, de modo a dar origem a escoamentos mais rápidos, diminuição do tempo de concentração e com muita frequência a picos de vazão elevado em algumas vezes acompanhados por alagamento [24].

Responsável por fazer o estudo hidrológico para o Igarapé do Mindu, por meio de simulações com os dados que obteve, estimou uma progressão na elevação do nível do igarapé por ocasião dos períodos de cheia [18]. A figura 16 é um modelo simplificado dessa evolução, na qual se mostra a previsão para todo o percurso do igarapé.

A área em verde claro indica a bacia de contribuição, as manchas em tons de verde mais escuro indicam o processo de impermeabilização estimado em escalas maiores à medida que escurecem, finalmente, em azul observam-se as manchas que representam os riscos de inundação como mostrada na figura acima. Para 2007 (imagem à esquerda) há a presença de dois focos de inundação e uma mancha de impermeabilização na parte intermediária do percurso do igarapé.

A imagem para uma previsão em 2020 mostra que os focos de inundação previstos em 2007 se unificam e prosseguem em direção à foz do igarapé. A área em tom verde é maior e tem o centro adensado.
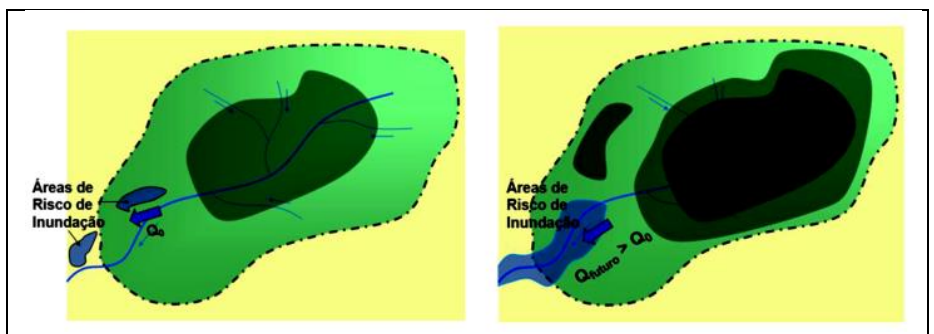

Figura 16: Previsão de inundações e permeabilização da bacia para os anos 2007 e 2020. Fonte: [18].

Em conformidade com [24], ao ser lançado um rápido olhar para a figura 16, que compara o perfil de superfície impermeabilizada em 2007 e o esperado para 2020 para a bacia de São Raimundo, nota-se uma evidente proporção entre o crescimento das manchas de inundação presentes na figura à medida que a superfície da bacia se torna mais impermeável.

O povoamento das bacias ocorre dos vales (próximo aos corpos hídricos) para as regiões mais elevadas [24].

Ao a Administração Pública ser desafiada por problemáticas dessa natureza, pode e deve tomar medidas ao seu alcance que visem a eliminação dessas catástrofes. [25] indica que as linhas de ação envolvem medidas estruturais (infraestrutura) e não estruturais (conscientização).

A tomada de medidas estruturais, demanda o conhecimento das variáveis envolvidas nos fenômenos naturais sobre os quais se busca o controle [26]. No caso de obras de drenagem, o que se deve procurar compreender são as precipitações que incidem sobre a área de interesse e a configuração topográfica que recepciona essas precipitações. Em posse dessas informações parte-se para o dimensionamento dos sistemas de macro e micro drenagem.

De acordo com o relatório técnico [18], o posto pluviométrico utilizado na coleta de dados usado nas simulações foi o posto 00360001 da Agência Nacional de Águas - ANA [27].

Este posto está localizado no município de Manacapuru e foi escolhido por possuir uma base de dados mais consistentes. A tabela 1 informa as maiores precipitações anuais coletadas a partir de 1972 até o ano de 2007, quando se deu o início dos levantamentos.

Tabela 1: Série histórica de chuvas do posto pluviométrico 00360001 (ANA).

\begin{tabular}{|ccc|}
\hline Ano & Data & Chuva $(\mathrm{mm})$ \\
\hline $\mathbf{1 9 7 2}$ & $11 / 01 / 1972$ & 33.7 \\
$\mathbf{1 9 7 3}$ & $01 / 01 / 1973$ & 88.0 \\
$\mathbf{1 9 7 4}$ & $03 / 01 / 1974$ & 114.8 \\
$\mathbf{1 9 7 5}$ & $12 / 01 / 1975$ & 94.8 \\
$\mathbf{1 9 7 6}$ & $02 / 01 / 1976$ & 150.6 \\
$\mathbf{1 9 7 7}$ & $04 / 01 / 1977$ & 142.8 \\
$\mathbf{1 9 7 8}$ & $02 / 01 / 1978$ & 176.0 \\
$\mathbf{1 9 7 9}$ & $04 / 01 / 1979$ & 95.2 \\
$\mathbf{1 9 8 0}$ & $01 / 01 / 1980$ & 75.6 \\
$\mathbf{1 9 8 1}$ & $03 / 01 / 1981$ & 94.0 \\
$\mathbf{1 9 8 2}$ & $03 / 01 / 1982$ & 93.0 \\
$\mathbf{1 9 8 3}$ & $03 / 01 / 1983$ & 92.0 \\
$\mathbf{1 9 8 4}$ & $04 / 01 / 1984$ & 83.6 \\
$\mathbf{1 9 8 5}$ & $04 / 01 / 1985$ & 153.2 \\
$\mathbf{1 9 8 6}$ & $03 / 01 / 1986$ & 125.0 \\
$\mathbf{1 9 8 7}$ & $08 / 01 / 1987$ & 86.7 \\
$\mathbf{1 9 8 8}$ & $11 / 01 / 1988$ & 228.7 \\
$\mathbf{1 9 8 9}$ & $03 / 01 / 1989$ & 110.7 \\
$\mathbf{1 9 9 0}$ & $04 / 01 / 1990$ & 164.0 \\
$\mathbf{1 9 9 1}$ & $01 / 01 / 1991$ & 105.9 \\
$\mathbf{1 9 9 2}$ & $08 / 01 / 1992$ & 68.8 \\
$\mathbf{1 9 9 3}$ & $03 / 01 / 1993$ & 107.0 \\
$\mathbf{1 9 9 4}$ & $01 / 01 / 1994$ & 51.2 \\
$\mathbf{1 9 9 5}$ & $10 / 01 / 1995$ & 37.0 \\
$\mathbf{1 9 9 6}$ & $06 / 01 / 1996$ & 90.0 \\
$\mathbf{1 9 9 7}$ & $01 / 01 / 1997$ & 126.0 \\
$\mathbf{1 9 9 8}$ & $11 / 01 / 1998$ & 62.0 \\
$\mathbf{1 9 9 9}$ & $02 / 01 / 1999$ & 64.2 \\
$\mathbf{2 0 0 0}$ & $04 / 01 / 2000$ & 95.0 \\
$\mathbf{2 0 0 1}$ & $12 / 01 / 2001$ & 107.3 \\
$\mathbf{2 0 0 2}$ & $01 / 01 / 2002$ & 140.1 \\
$\mathbf{2 0 0 3}$ & $09 / 01 / 2003$ & 57.0 \\
$\mathbf{2 0 0 4}$ & $12 / 01 / 2004$ & 127.3 \\
$\mathbf{2 0 0 5}$ & $02 / 01 / 2005$ & 136.8 \\
$\mathbf{2 0 0 6}$ & $11 / 01 / 2006$ & 112.0 \\
$\mathbf{2 0 0 7}$ & $01 / 01 / 2007$ & 69.7 \\
\hline & Re & \\
\hline
\end{tabular}

Fonte: Retirar (2018), [27].

O gráfico apresentado na figura 17 é um hietograma que estuda o comportamento das chuvas de TR 10 a TR 100. 


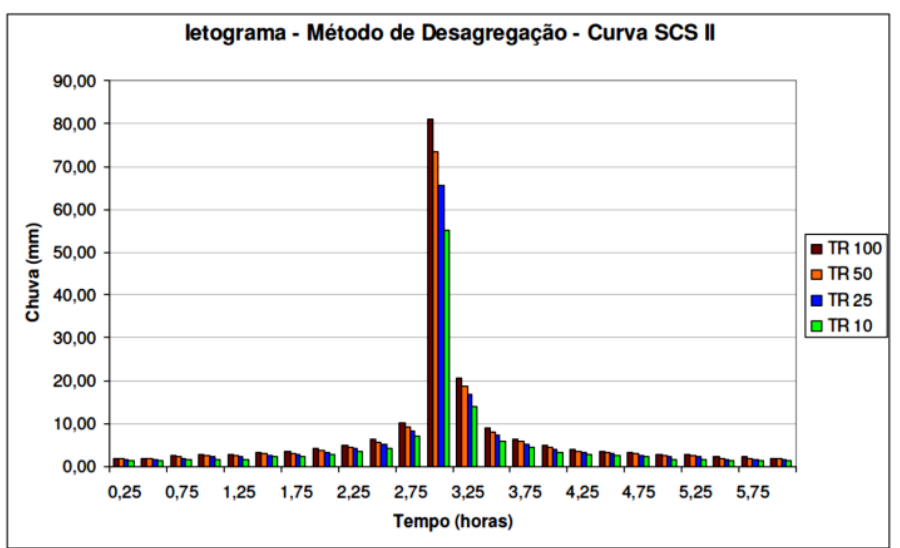

Figura 17: Hietograma de Manaus.

Fonte: [18].

Constata-se que o maior acúmulo de precipitação que costuma acontecer na região se dá entre $2,5 \mathrm{~h}$ a $3,5 \mathrm{~h}$ de precipitação, conforme o levantamento das curvas IDF.

De suas apurações sobre a condição das chuvas, o que se expõe neste trabalho é o parâmetro que norteou os cálculos para dimensionamento. Verificou-se que o tempo de concentração para a área de interesse costuma ocorrer em um intervalo de tempo em torno de 3 horas. Isso mesmo para TR 100. Porém através da pesquisa surge um questionamento sobre uma origem fundamental de dados.

Na coleta das séries históricas de chuva utilizou-se a estação 00360001 localizada no município de Manacapuru [18]. Atualmente, há uma estação instalada em Manaus. É de maior precisão a obtenção dessas informações o mais próximo possível do local de estudo.

A figura 18 revela a distribuição da densidade pluviométrica no território nacional, e é possível notar que o mapeamento mostra um aumento de densidade à medida que se desloca para a esquerda no sentido Manaus - Manacapuru.

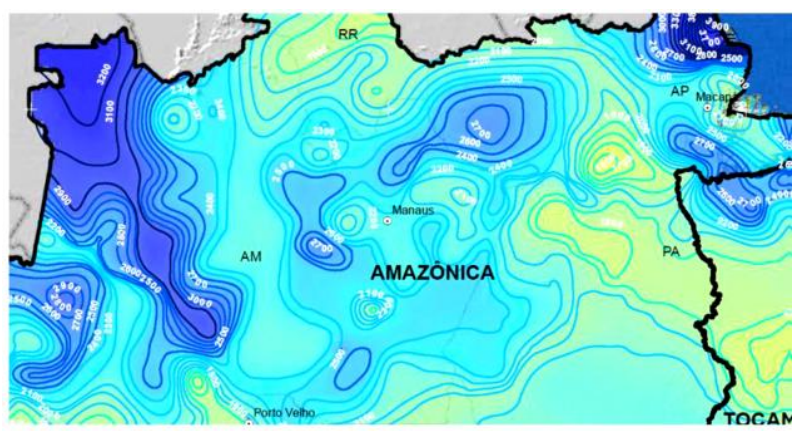

Figura 18: Detalhe na densidade pluviométrica no Amazonas. Fonte: [28]

Essa afirmação é plausível, ao considerar que a figura 18 demonstra a distribuição de densidade pluviométrica exibida no território brasileiro, entendem-se duas peculiaridades: a densidade pluviométrica sofre variações de um ponto geográfico para outro; e à medida que o observador desloca a visão sobre o mapa no sentido Manaus-Manacapuru (oeste) a densidade pluviométrica aumenta.

O motivo que condicionou a escolha do referido posto, foi o de ter este uma série histórica mais consistente para a região, conforme se vê na tabela 1, onde há registros desde o ano de 1972, no ano em que os estudos começaram. Em consulta ao banco de dados da ANA [29], os dados para o de Manaus são insignificantes para a mesma época. Porém mesmo com dados brutos, listados na tabela 2 e comparados em um gráfico na figura 19, e novamente, observado o exposto na figura 18 , é de bom alvitre uma revisão da chuva de projeto.

O método escolhido dentre outros e aplicado para definir como a topografia do local recebe essas precipitações foi o SCS (atualmente denominado NCRS) [26].

A ideia com essa técnica é a de discretizar a bacia principal em bacias menores e estimar a contribuição que cada sub-bacia fornecerá para a vazão do curso principal. Para isso procede-se uma classificação das características predominantes do solo que compõe cada uma.

Já há na cidade de Manaus, estações de coleta de dados pluviométricos. Um exemplo disso é a estação 00359005, instalada na sede da Companhia de Pesquisa de Recursos Hídricos - CPRM. $\mathrm{Na}$ tabela 2, foram utilizados dados brutos dos valores das precipitações máximas entre os anos de 1998 a 2009 de maneira que a possibilitar uma comparação entre os valores apurados para Manaus e Manacapuru e também os meses em que os eventos foram registrados.

Tabela 2: Co96mparativo das precipitações máximas entre Manaus e Manacapuru, respectivamente.

\begin{tabular}{|lccc|}
\hline Ano & Mês & Chuva $(\mathbf{m m})$ & Chuva $(\mathbf{m m})$ \\
\hline $\mathbf{1 9 9 8}$ & Janeiro & 94,6 & 47,1 \\
$\mathbf{1 9 9 9}$ & Maio & 88,5 & 64,2 \\
$\mathbf{2 0 0 0}$ & Abril & 166,6 & 82,3 \\
$\mathbf{2 0 0 1}$ & Novembro & 176,1 & 107,3 \\
$\mathbf{2 0 0 2}$ & Janeiro & 67,1 & 140,1 \\
$\mathbf{2 0 0 5}$ & Maio & 97,4 & 136,8 \\
$\mathbf{2 0 0 6}$ & Dezembro & 110,4 & 112 \\
$\mathbf{2 0 0 7}$ & Dezembro & 84,7 & 105,4 \\
$\mathbf{2 0 0 8}$ & Março & 96,5 & 126,2 \\
$\mathbf{2 0 0 9}$ & Fevereiro & 71,8 & 72,4 \\
\hline
\end{tabular}

Fonte: [28].

O gráfico exposto por meio da figura 19 mostra a variação das apurações das estações de Manaus (00359005) e de Manacapuru (00360001). Dos anos de 1998 a 2001 as precipitações de maior escala foram coletadas em Manaus. Em 2006 os eventos de maior grandeza atingiram certa compatibilidade até o ano de 2009.

Valor máximo de precipitações por ano (dados brutos)

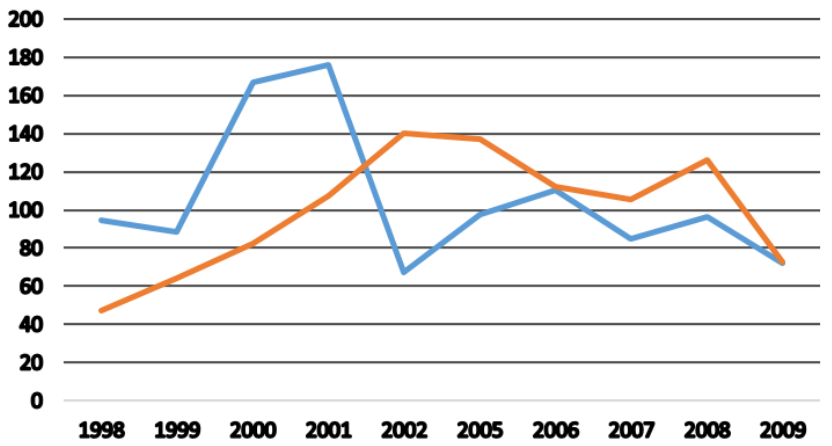

Figura 19: Comparativo das precipitações entre Manaus e Manacapuru.

Fonte: Autores, (2017).

Processado em software GIS, chegou-se à discretização da Bacia de São Raimundo em 68 sub-bacias. Sua disposição está apresentada por meio do mapa da figura 20. 


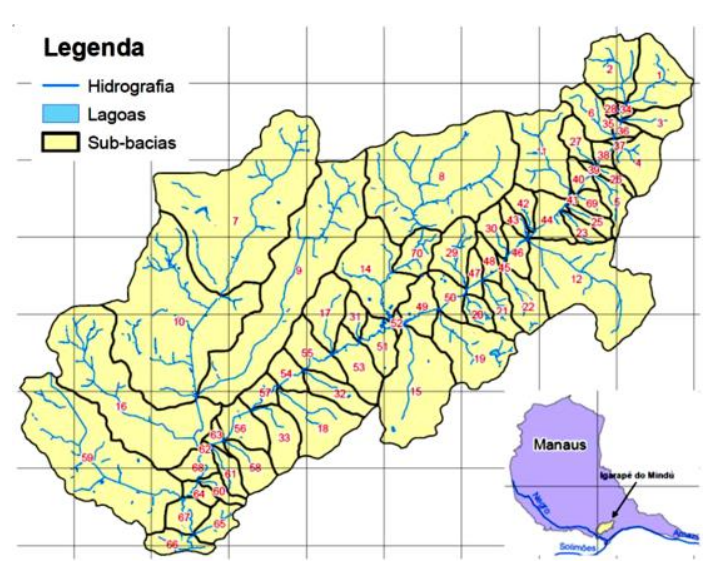

Figura 20: Sub-bacias da bacia de São Raimundo. Fonte: [18].

As figuras uso e ocupação são fruto do cruzamento dos dados que relacionam as sub-bacias (figura 20), tipo de solo e sua ocupação ou uso. Por meio desses levantamentos obtém-se a confirmação da predominância geológica e topográfica, dados endossados pela observação empírica de solo com presença de muito barro (argiloso) e com presença de muitas declividades.

Para [24-26] entendem este método, como boa fonte de interpretação da relação bacia/precipitação. Muitos profissionais da Engenharia e Hidrólogos, quando confrontados por desafios como o caso de estudo do comportamento de bacias, adotam o método SCS (Soil Conservation Service), atualmente chamado método NRCS (Natural Resources Conservation Service) [30]. O método consiste em relacionar características do solo para a determinação de um número que identifique sua capacidade de saturação sob uma precipitação, este é o CN (curve number, ou número de curva).

A figura 21 representa os tipos de solo que compõem a bacia e a figura 22 representa a ocupação da área da bacia. Quanto ao tipo, é possível verificar a predominância de solo argiloso com presença de declividades, quanto à ocupação percebe-se que as manchas indicativas de cobertura vegetal são escassas.
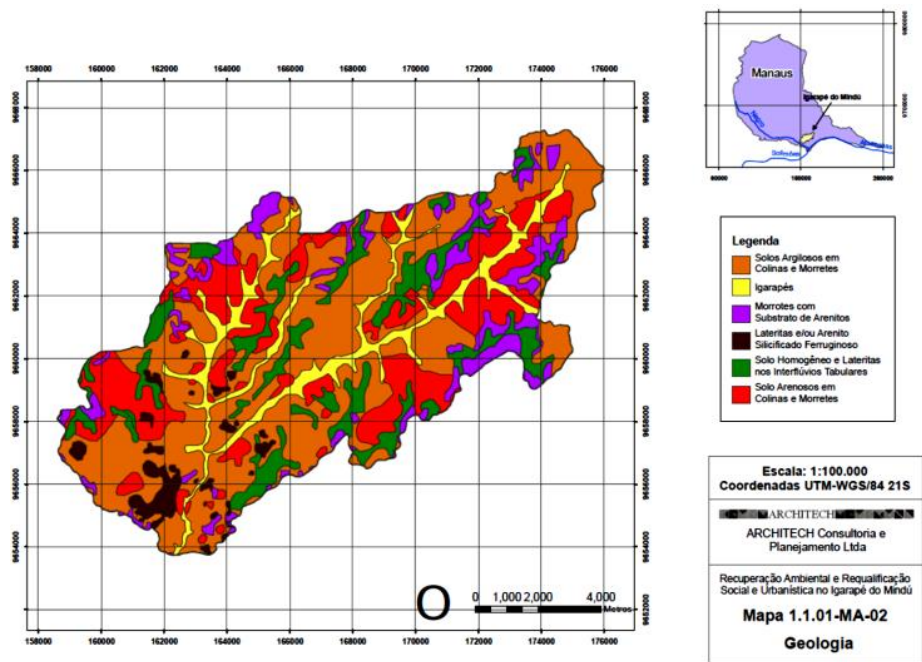

Figura 21: Tipos de solo da Bacia de São Raimundo. Fonte: [18].

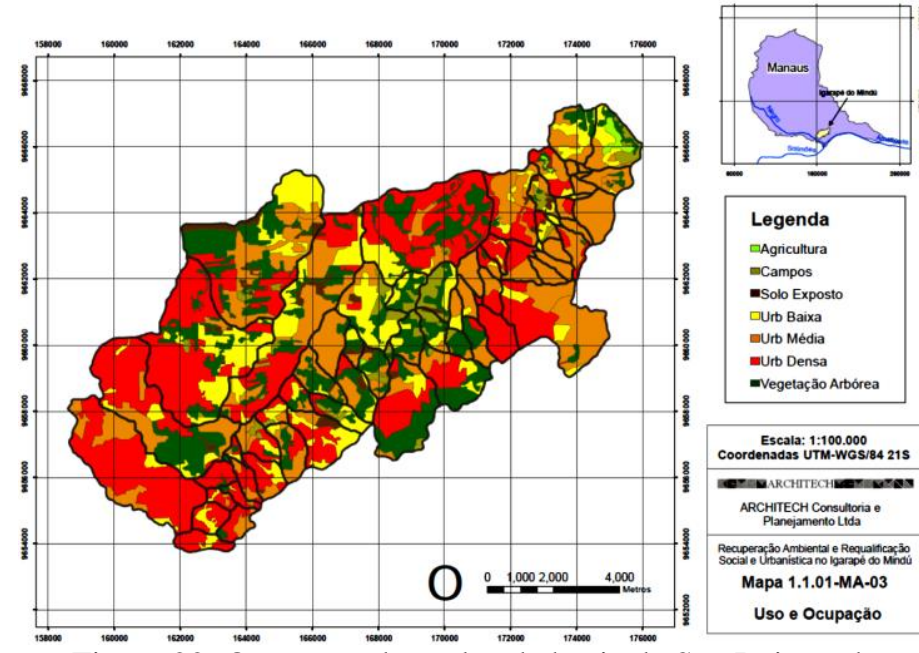

Figura 22: Ocupação dos solos da bacia de São Raimundo. Fonte: [18].

Com as condições geológicas e de cobertura de solo apurados em 2007 sobre os solos da bacia de São Raimundo, o que se obteve como resultado do $\mathrm{CN}$ (curve number) médio de cada sub-bacia.

Na figura 23 tem-se um hidrograma, que é o gráfico que busca apontar as leituras da vazão durante uma chuva. No caso, este é acompanhado de uma legenda que enumera as fases do fluxo da água na bacia em consequência da chuva precipitada.

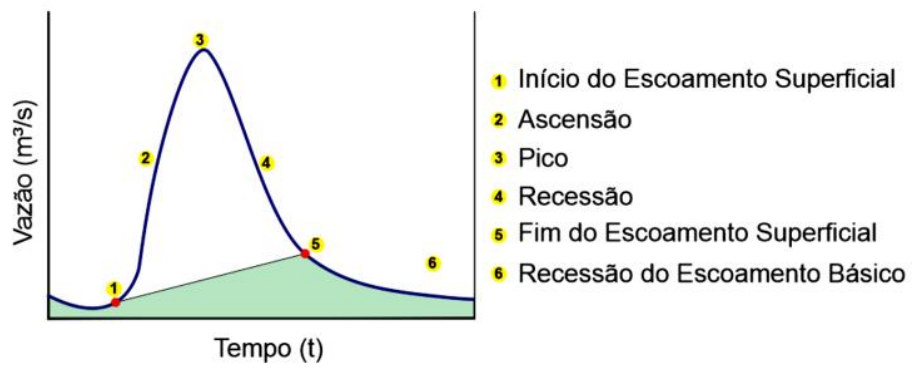

Figura 23: Hidrograma.

Fonte: Adaptado de [31].

Com esse número obtido torna-se possível fazer leituras no hidrograma (figura 23), de maneira que se procure manipular ou conhecer as variáveis envolvidas para a obtenção daquilo que se defina como ideal para o projeto. Conforme [26], busca-se um melhor entendimento de como a precipitação se comporta dentro de uma bacia e se obtém, tanto o que escoa pela superfície (escoamento superficial), quanto o que escoa pela camada subterrânea (escoamento básico), e dessa forma é possível conhecer melhor os detalhes da precipitação e o tempo médio que leva para que toda a bacia comece a contribuir para a água que escoa pela superfície (tempo de concentração).

Ao se tomar como referência a R. João Câmara, de uma intersecção com a mesma, tem início a Av. Nathan Xavier de Albuquerque, deste ponto de partida, segue um trecho em que esta é quase paralela ao igarapé por uma extensão de aproximadamente $600,00 \mathrm{~m}$. Isso é visto na figura 24 através de uma imagem do Google Maps [10]. 


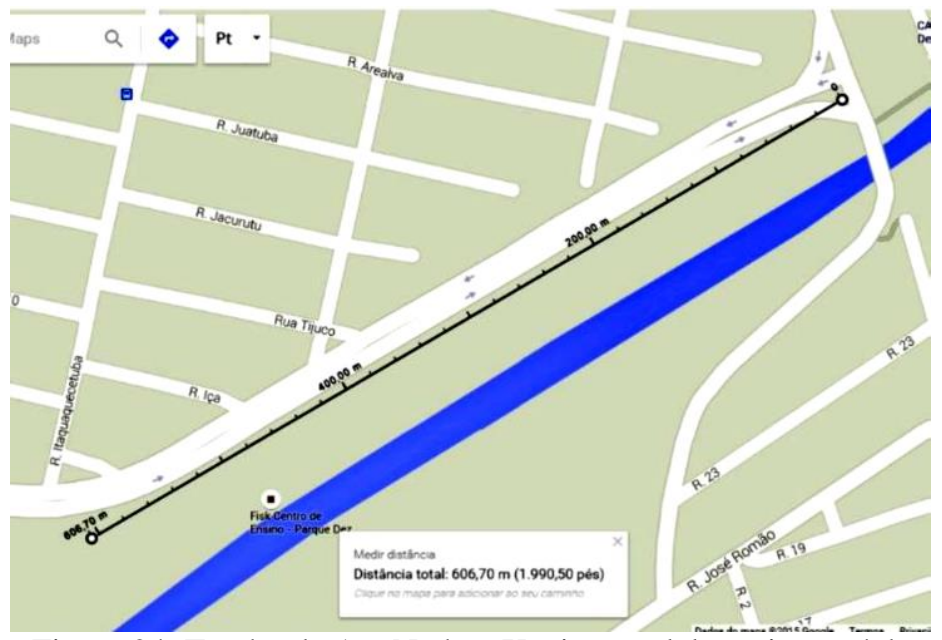

Figura 24: Trecho da Av. Nathan Xavier paralelo ao igarapé do Mindu.

Fonte: [10].

As figuras 25 e 26 mostram a medição que aponta as distâncias entre a avenida referida e o limite da margem do igarapé do Mindu. A figura 25, representa a menor distância, que mede cerca de $34,00 \mathrm{~m}$. Para o trecho, a largura do leito do igarapé de que trata este estudo varia em torno de $20,00 \mathrm{~m}$ (quase metade da menor distância).

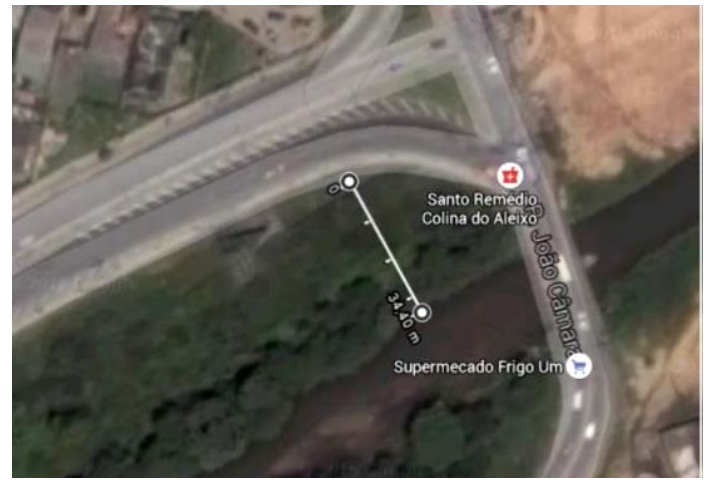

Figura 25: Menor distância o trecho e a margem. Fonte: [10].

De acordo com o prosseguimento desta avenida, há um distanciamento, de modo que ao terminar os $600,00 \mathrm{~m}$ de comprimento o afastamento entre ela e a margem do Mindu mede cerda de 90,00m (figura 26).

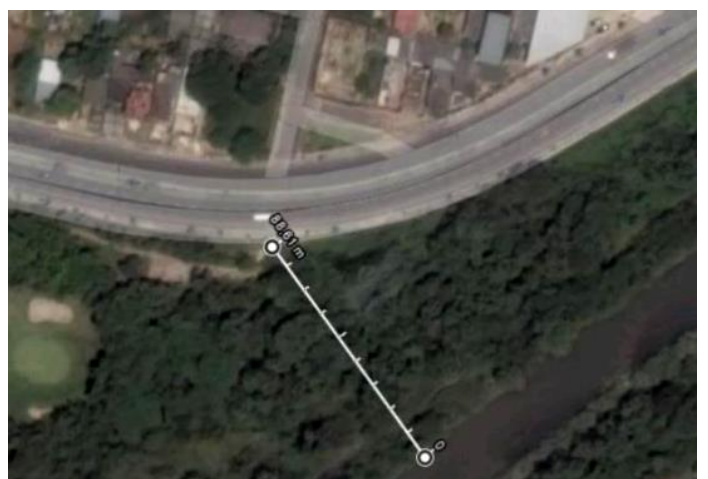

Figura 26: Maior distância entre o trecho e a margem. Fonte: [10].

Pela figura 24 constata-se que a mesma é praticamente paralela ao igarapé do Mindu por uma extensão aproximada de 600,00m. a menor distância mede cerca de 34,00m (figura 25), enquanto a maior mede cerca de $90,00 \mathrm{~m}$ (figura 26).

A figura 27 traz o detalhe de uma versão preliminar do projeto de implantação da Av. Nathan Xavier de Albuquerque e a previsão de Bocas-de-lobo a serem instaladas nos bordos da pista de rolamento, no desenho, estes dispositivos hidráulicos estão assinalados por quadrados com círculos dentro de seu perímetro, ambos em contorno vermelho, conforme indicam as setas amarelas.

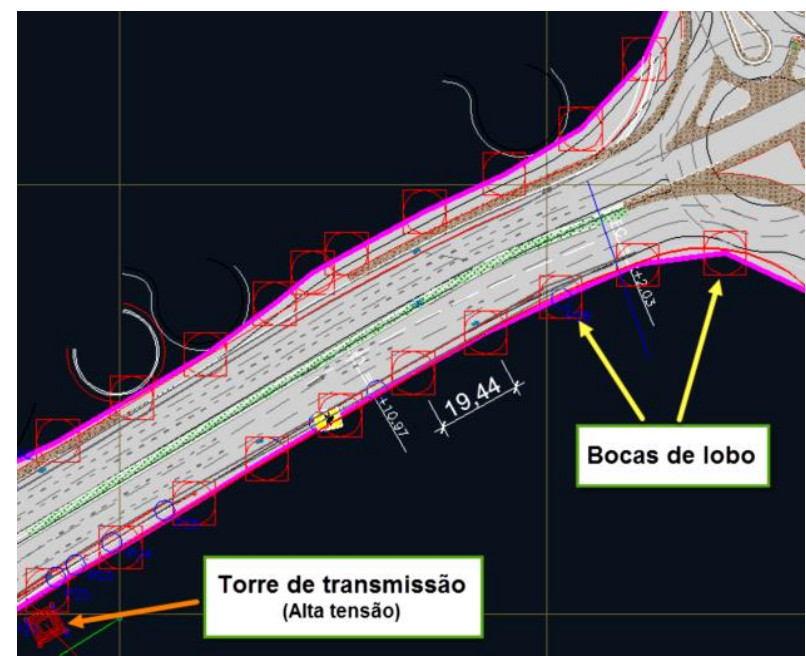

Figura 27: Detalhe de projeto preliminar da Av. Nathan Xavier de Albuquerque.

Fonte: [18].

Como ponto de referência conta-se com uma torre de transmissão de alta tensão e observa-se que a partir dela, pela borda inferior, até a interceptação com a R. João Câmara consta a previsão de 10 bocas-de-lobo que distam entre si cerca de 20,00m.

Um exemplo de uma aplicação que averigua esses valores na execução dos atos públicos pode ser praticado ao se avaliar a figura 27 em comparação com a implantação que foi executada. O que se observa na figura é um modelo preliminar de instalação de bocas de lobo em direção praticamente paralela nos bordos da pista.

A figura 28 integra o resultado da inspeção visual de campo feita no mês de setembro do ano de 2015 . No canto inferior direito, a imagem tem contornada em linha amarela, uma mancha indicativa da presença de água acumulada, ao passo que quase paralela, à margem esquerda da pista, está uma boca-de-lobo dupla enfatizada por uma elipse de cor vermelha.

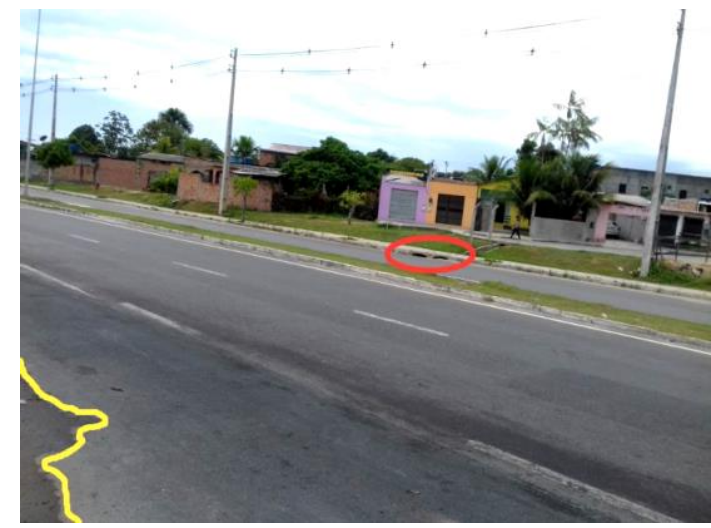

Figura 28: Acúmulo de água na via (09/2015). Fonte: Autores, (2017).

Pela figura 29, é visto o acúmulo crítico, que parte deste ponto para o restante da guia e pista. Seja salientado que sua localização 
está exatamente paralela à direção da boca-de-lobo mostrada na figura 28.

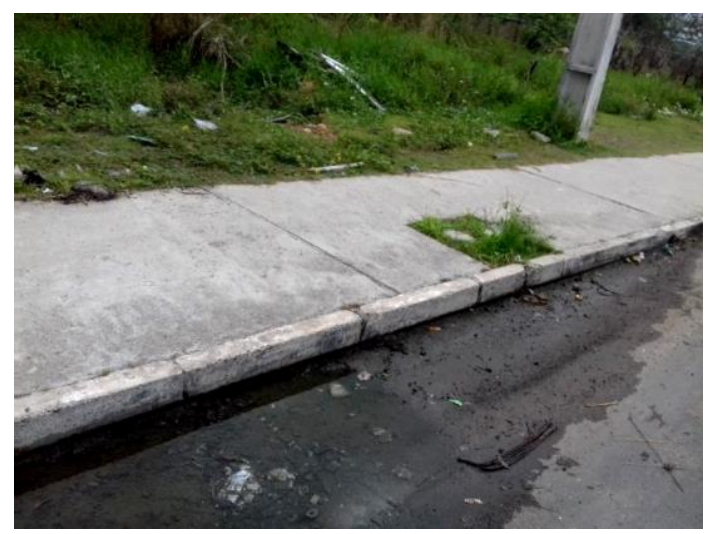

Figura 29: Possível ausência de dispositivo hidráulico. Fonte: Autores, (2017).

Durante a visita não foi encontrada nenhuma origem que pudesse explicar a fonte da água acumulada (torneira nas proximidades ou encanamento rompido)

Ao se verificar a implantação, o que se constata é uma quantidade insuficiente deste dispositivo hidráulico, de maneira que nas figuras 28 e 29 é possível ver a presença de acúmulo de água. Por ocasião da visita técnica, não houve chuva e não foi observada nem uma fonte que pudesse dar origem ao empoçamento, o que indica que o acúmulo de água é persistente. É interessante frisar, que o mês de setembro não apresenta precipitação média elevada na região.

As figuras 30 e 31, retratam as condições de conservação nas áreas próximas à parte da via que apresentava retenção de água. $\mathrm{Na}$ figura 30 o que se vê é uma patologia denominada Couro de Jacaré, caracterizada pela presença de trincas em sentido longitudinal e transversal, o comprimento da área afetada é de pouco mais de $1,50 \mathrm{~m}$ e a largura de aproximadamente $0,50 \mathrm{~m}$. Esta não é a única manifestação dessa patologia nas imediações. Na parte inferior da imagem, percebe-se um processo de erosão em andamento.

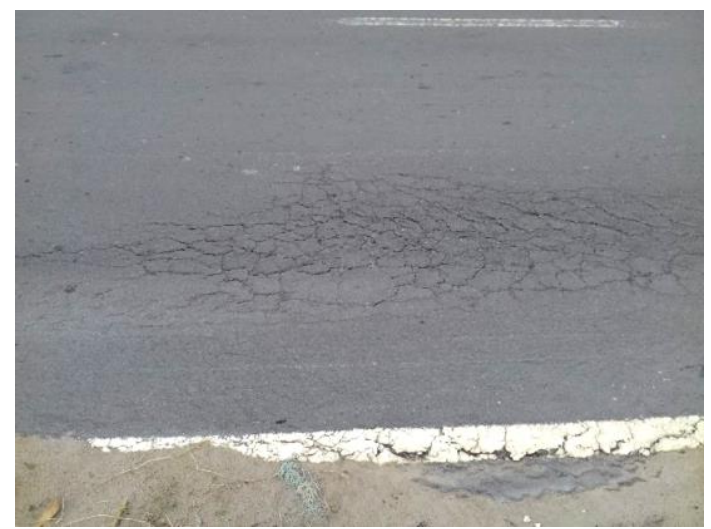

Figura 30: Trincas do tipo Couro de Jacaré. Fonte: Autores, (2017).

Duas patologias podem ser vistas por meio da figura 31. Neste caso, trata-se de Escorregamento do Revestimento Betuminoso associado a um afundamento, essas patologias estão assinaladas por linhas vermelhas e há um círculo azul que indica o empoçamento de água está próximo a elas.

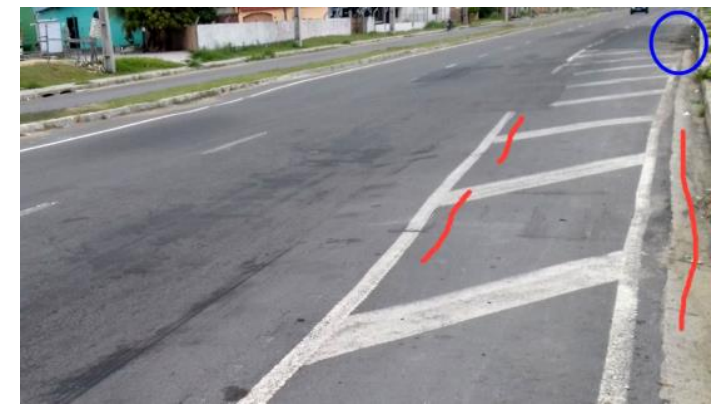

Figura 31: Afundamento e Escorregamento de Revestimento Betuminoso.

Fonte: Autores, (2017).

A figura 32 demonstra a disposição que é o padrão de execução de uma pavimentação. O revestimento é a parte com a qual os veículos terão contato. Como camadas que dão sustentação ao concreto asfáltico, e por fim ao revestimento está a base a ser executada com material granular e a sub-base, também composta por material granular ou pelo solo natural in situ.

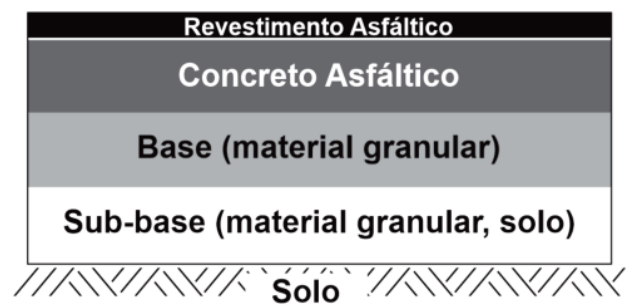

Figura 32: Camadas de revestimento asfáltico em pavimento flexível.

Fonte: Adaptado de [32].

Pela compreensão do conceito de umidade ótima apresentado por [33], pode-se apresentar como consequência dessa zona em que a água permanece por mais tempo, a presença de patologias no revestimento asfáltico que estão associadas à perda da compacidade ideal das camadas de base, de modo a darem sustento às camadas superiores (figura 32), frente aos esforços aplicados pelos veículos sobre o revestimento asfáltico.

Para [34], os maiores desafios na gestão das problemáticas públicas permeadas por causas ambientais consiste no gerenciamento responsável, e não somente dos fatores tecnológicos ou financeiros. Possivelmente, por uma busca de cumprimento de prazo, a Avenida Nathan Xavier de Albuquerque dá mostras de deterioração de modo precoce, uma vez que a inauguração ocorreu em março de 2013 como informa a página eletrônica da Prefeitura de Manaus.

A cerca vista na figura 33 é parte da obra de implantação da Av. Nathan Xavier de Albuquerque. Nota-se lixo depositado onde há restrição imposta pela cerca. O que se pode discernir é um aglomerado de sacolas plásticas, o que comumente é usado para embalar resíduos domésticos. 


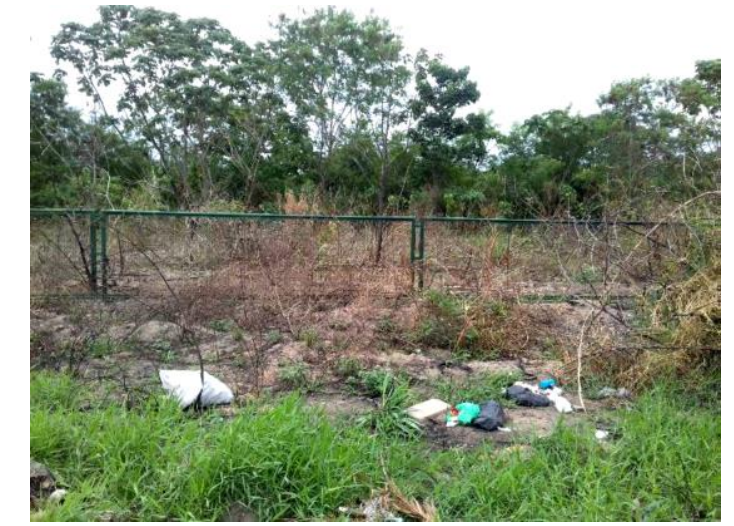

Figura 33: Lixo depositado próximo à delimitação da APP Fonte: Autores, (2017).

Em um ponto próximo e ainda diante da região limítrofe, expõe-se na figura 34, uma carcaça de geladeira sobre entulho residual de materiais construtivos. Apesar de não ser percebida facilmente, sabe-se que há a cerca, pela formação assumida pelo capim que a recobre.

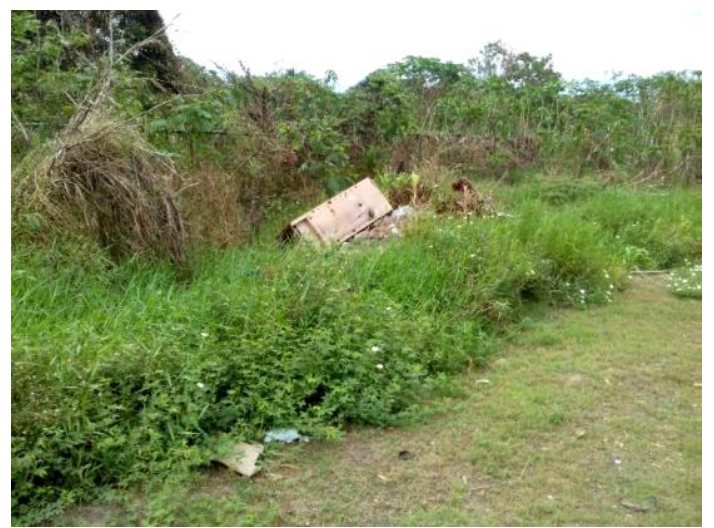

Figura 34: Carcaça de geladeira e entulhos próximos à cerca de proteção da APP.

Fonte: Autores, (2017).

No sentido R. João Câmara/Av. Governador José Lindoso (Av. das Torres), A figura 35 mostra as condições da margem oposta à que as Figuras 33 e 34. Há resquício de umidade.

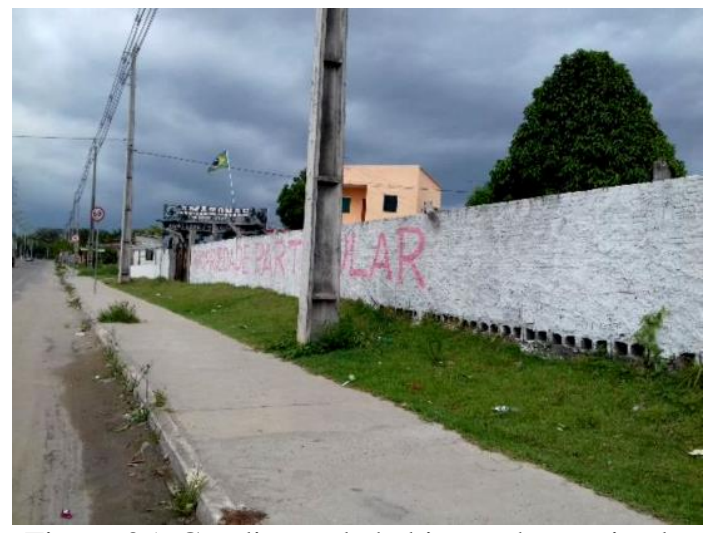

Figura 35: Condições de habitação humanizada.

Fonte: Autores, (2017).

Novamente em ênfase aos resultados no campo da conservação ambiental, observem-se as figuras 33, 34 e 35. Nas duas primeiras. Percebe-se que a imposição do limite torna-se de grande importância para evitar que mesmo lixos de grandes dimensões passem a ocupar o leito do igarapé do Mindu, na terceira o que se vê é uma situação que preserva o valor de dignidade da pessoa humana, com área a receber estrutura de saneamento e sem degradação, situação bem melhor do que a presenciada na figura 9 .

\section{CONCLUSÃO}

Ao considerar as responsabilidades que pesam sobre o Administrador Público advindas dos acúmulos de direitos sociais, os quais culminam com o ganho de direitos ligados à temática ambiental na busca por uma qualidade de vida melhor da população e na responsabilidade em manter fauna, flora e recursos naturais de qualquer circunscrição que esteja sob sua jurisdição.

A despeito de que se espere por parte das obras de Engenharia Civil uma contribuição apenas operacional, esse campo de atuação como uma Ciência que abriga e coaduna competências multidisciplinares pode bem mais que isso.

Através do plano de Recuperação Ambiental e Requalificação Social e Urbanística no Igarapé do Mindu, a Prefeitura Municipal de Manaus, tem tomado ações que têm propiciado meios para recuperação e manutenção da fauna e flora de um corpo hídrico bastante relevante.

Constatou-se a ocorrência de condições inapropriadas de habitação, degradação ambiental, e eventos de inundação em proporções alarmantes com previsão de sinistros ainda maiores para anos mais próximos, caso os órgãos competentes não pratiquem nenhuma intervenção.

Por toda a participação na obtenção de dados e interpretação dos mesmos, na implementação dos projetos que têm modificado a realidade de inúmeras famílias de modo a trazer a estas, mais dignidade, nas ações de recuperação e preservação de meios degradados ou sobre risco e por sua possibilidade de atuação como recurso fiscalizador, entende-se que o profissional que pratica a Engenharia Civil de modo científico e crítico é um membro essencial para a sociedade. Desde que associada à competência técnica, esteja à idoneidade para diante dos que não gozam do mesmo preparo, dedicar seus melhores esforços para um desenvolvimento equilibrado, consciencioso e eficaz dos anseios sociais e consequentemente ambientais.

É imprescindível que essas virtudes estejam ao alcance do Poder Público, que ao poder manuseá-lo logrará resultados mais consistentes e efetivos das práticas que adota.

Sugere-se por meio deste estudo que os órgãos competentes possam criar programas de desenvolvimento técnico para os profissionais atuantes na região, a fim de proporcionar maiores subsídios de mão de obra qualificada e de cidadãos mais interativos. Além de promover a adoção da prática de convênios atuantes, com as instituições de ensino responsáveis pela formação desses profissionais de modo a confrontá-los com desafios de magnitude significativa.

\section{REFERÊNCIAS}

[1] L. R. BROWN, "Eco-Economia: construindo uma economia para a terra," Salvador: Uma, p. 85, 2003.

[2] J. RIFkIN, "O fim dos empregos: o contínuo crescimento do desemprego em todo o mundo," São Paulo: M. Books, 2004.

[3] S. Herculano, M. F. d. S. Porto, and C. M. d. Freitas, "Qualidade de vida \& riscos ambientais," in Qualidade de vida \& riscos ambientais, ed, 2000 .

[4] J. R. d. Moraes, J. P. d. L. Moreira, and R. R. Luiz, "Associação entre o estado de saúde autorreferido de adultos e a área de localização do 
domicílio: uma análise de regressão logística ordinal usando a PNAD 2008," Ciência \& saúde coletiva, vol. 16, pp. 3769-3780, 2011.

[5] M. E. B. Sposito, "Capitalismo e urbanização," ed: Contexto São Paulo, 1988.

[6] L. Trevisan, "Os usos do território brasileiro e o imperativo da logística: uma análise a partir da Zona Franca de Manaus," 2012.

[7] T. S. Barbosa and M. Furrier, "OCUPAÇÕES IRREGULARES E IMPACTOS SÓCIO-AMBIENTAIS ÀS MARGENS DO RIO SANHAUÁ, PARAÍBA/BRASIL," Revista Percurso, vol. 5, pp. 91-107, 2013

[8] E. F. S. d. Araújo, "Os impactos arquitetônicos e urbanísticos do programa PROSAMIM na paisagem de Manaus," 2011.

[9] R. P. Rabello and Z. A. L. Rodrigues, "Planejamento e sustentabilidade urbana: ações de proteção dos Igarapés de Manaus," Revista Meio Ambiente e Sustentabilidade, vol. 3, pp. 80-101, 2013.

[10] G. Brasil. (2019, 25 de Novembro). Dados do Mapa. Available: https://www.google.com.br/maps/preview

[11] F. AMAZÔNIA, "Relatório de atividades 2013," ed: Brasília, 2014.

[12] L. Boff, "História da sustentabilidade," Leonardo, vol. 26, pp. 112007, 2014.

[13] S. F. do Brasil, "Constituição da república federativa do Brasil," Brasília: Senado Federal, Centro Gráfico, 1988.

[14] A. A. Maciel Filho, C. D. Góes-Júnior, J. A. Câncio, L. Heller, L. Moares, M. L. Carneiro, et al., "Interfaces da gestão de recursos hídricos e saúde pública," Interfaces da gestão de recursos hídricos. Desafios da lei de águas de, pp. 396-420, 1997.

[15] J. C. T. Crivellari, "O novo código florestal (Lei No. 12.651/12) e suas implicações no contexto da sustentabilidade socioeconômica ambiental," 2015.

[16] S. P. M. Batista, "Algumas considerações sobre as intervenções do Prosamim no ordenamento da cidade de Manaus," SIMPÓSIO NACIONAL DE GEOGRAFIA POLÍTICA, vol. 3, pp. 1376-1393, 2013.

[17] C. A. Alvares Soares Ribeiro, V. P. Soares, A. M. Santos Oliveira, and J. Marinaldo Gleriani, "O desafio da delimitação de áreas de preservação permanente," Revista Árvore, vol. 29, 2005.

[18] A. Macdonald, "The visual issue-An investigation into the techniques and methodology used in windfarm computer visualisations," ed: Inverness: Architech Animation Studios, 2007.

[19] A. R. Queiroz, "Prosamim: desafios de implantação de infraestrutura de saneamento e ocupação do solo urbano na cidade de Manaus, Amazonas," 2009.

[20] A. Mazza, Manual de direito administrativo: Editora Saraiva, 2018.

[21] K. R. M. Cassiano, "PROGRAMA DE PÓS-GRADUAÇÃO EM

GEOGRAFIA," Universidade Federal de Santa Catarina, 2013.
[22] M. H. C. Botelho, Águas de chuva: engenharia das águas pluviais nas cidades: Edgard Blucher, 2006.

[23] T. V. d. Carvalho Neto, "O princípio da impessoalidade nas decisões administrativas," Universidade de São Paulo, 2015.

[24] A. Canholi, Drenagem urbana e controle de enchentes: Oficina de textos, 2015.

[25] C. E. Tucci, "Inundações urbanas," Porto Alegre: ABRH/RHAMA, vol. 11, 2007.

[26] J. E. Gribbin, Introdução à hidráulica, hidrologia e gestão de águas pluviais: Cengage Learning, 2009.

[27] J. A. d. Lima, M. V. R. Dambros, M. A. P. M. d. Antonio, J. G. Janzen, and M. Marchetto, "Potencial da economia de água potável pelo uso de água pluvial: análise de 40 cidades da Amazônia," 2011.

[28] S. S. MARINI, "Mapeamento da hidrografia da Amazônia por meio de imagens orbitais após estudo hidrológico preliminar do complexo fluvial Solimões/Amazonas," XI Simpósio Brasileiro de Sensoriamento Remoto. Resumo Expandido, Belo Horizonte, pp. 2541-2548, 2003.

[29] J. R. Fontoura, D. G. A. Piccilli, R. Tassi, V. G. Geller, J. R. Favaretto, and G. H. Froemming, "Geoferramenta para Aquisição Automática de Dados Pluviométricos a partir do QGIS," ed: Anais, 2016.

[30] S. CUNHA, F. SILVA, T. MOTA, and M. PINHEIRO, "Avaliação da acurácia dos métodos do SCS para cálculo de precipitação efetiva e hidrogramas de cheia," RBRH-Revista Brasileira de Recursos Hídricos, vol. 20, pp. 837-848, 2015.

[31] F. Campos, "Departamento de Engenharia Hidráulica e Ambiental," Escola Politécnica| Universidade de São Paulo| Tel.:(11), pp. 3091-5444.

[32] P. F. A. Silva, Manual de patologia e manutenção de pavimentos: PINI, 2008.

[33] H. P. Caputo, "Mecânica dos solos e suas aplicações," in Mecânica dos solos e suas aplicaçoes, ed: LTC, 1981.

[34] L. E. Sánchez, Avaliação de impacto ambiental: Oficina de Textos, 2015. 